\title{
The Role of Outside-School Factors in Science Education: A two-stage theoretical model linking Bourdieu and Sen, with a case study
}

Tuba Gokpinar ${ }^{\mathrm{a}^{*}}$ and Michael Reiss ${ }^{\mathrm{a}}$

${ }^{a}$ UCL Institute of Education, University of College London, London, UK

The literature in science education highlights the potentially significant role of outside-school factors such as parents, cultural contexts and role models in students' formation of science attitudes and aspirations, and their attainment in science classes. In this paper, building on and linking Bourdieu's key concepts of habitus, cultural and social capital, and field with Sen's capability approach, we develop a model of students' science-related capability development. Our model proposes that the role of outside-school factors is twofold, first, in providing an initial set of science-related resources (i.e., habitus, cultural and social capital), and then in conversion of these resources to science-related capabilities. The model also highlights the distinction between science-related functionings (outcomes achieved by individuals) and science-related capabilities (ability to achieve desired functionings), and argues that it is necessary to consider science-related capability development in evaluating the effectiveness of science education. We then test our theoretical model with an account of three Turkish immigrant students' science-related capabilities and the role of outside-school factors in forming and extending these capabilities. We use student and parent interviews, student questionnaires and in-class observations to provide an analysis of how outside-school factors influence these students' attitudes, aspirations and attainment in science.

Keywords: Outside school factors; Science aspirations; Science capabilities; Bourdieu; Sen

*Corresponding author. Department of Curriculum, Pedagogy and Assessment

UCL Institute of Education, University College London, 20 Bedford Way London, WC1H

OAL, UK. Email:

tgokpinar@ioe.ac.uk 


\section{The Role of Outside-School Factors in Science Education: A two-stage theoretical model linking Bourdieu and Sen, with a case study}

The literature in science education highlights the potentially significant role of outsideschool factors such as parents, cultural contexts and role models in students' formation of science attitudes and aspirations, and their attainment in science classes. In this paper, building on and linking Bourdieu's key concepts of habitus, cultural and social capital and field with Sen's capability approach, we develop a model of students' science-related capability development. Our model proposes that the role of outside-school factors is twofold, first, in providing an initial set of science-related resources (i.e., habitus and cultural and social capital), and then in conversion of these resources to science-related capabilities. The model also highlights the distinction between science-related functionings (outcomes achieved by individuals) and science-related capabilities (ability to achieve desired functionings), and argues that it is necessary to consider science-related capability development in evaluating the effectiveness of science education. We then test our theoretical model with an account of three Turkish immigrant students' science-related capabilities and the role of outside-school factors in forming and extending these capabilities. We use student and parent interviews, student questionnaires and in-class observations to provide an analysis of how outside-school factors influence these students' attitudes, aspirations and attainment in science. 


\section{Introduction}

School students between the ages of 5 and 16 spend only around $18 \%$ of their waking hours per day in formal education (Bransford, 2006). Consequently, a large stream of research in science education has focused on the role of outside-school factors in shaping students' attitudes, aspirations and attainment in science (Braund \& Reiss, 2006; Crowley et al., 2001; Dabney et al., 2013; Dierking \& Falk, 1994; Hall \& Schaverien, 2001). If we want to understand students' attitudes to the study of science in a comprehensive manner, we should pay close attention to the cultural contexts, daily lives and families in which students are situated and where their attitudes and inspirations are largely produced (Osborne, 2007; Archer et al., 2010).

Outside-school factors include parents and their actions, role models in the extended family or friends' network, cultural contexts such as cultural values, daily activities and practices, and other out-of-school experiences. Out-of-school experiences can be defined as informal experiences that include a range of learning activities from daily activities found at home, such as discussions among family members and information received through the media, to recreational activities, such as gardening, hiking and visiting zoos, aquaria and museums (National Research Council, 2009). Students' out-of-school experiences might have a major impact on their science learning because these experiences provide opportunities for students to construct, modify and reflect on the content knowledge they gain in the classroom (Tran, 2011). When students are involved in science-related activities outside the school in a real, personal and relevant way, they typically experience much deeper and more meaningful science learning (Calabrese Barton, 1998; Fusco \& Calabrese Barton, 2001; Rahm, 2002).

In this paper, we address the following research question: Through which mechanisms do families, cultural contexts and other outside-school factors influence students' participation in science?

In order to address this question, we first develop a theoretical model by synthesising Bourdieu (1977, 1993) and Sen (1992, 1993), and explain how outside-school factors can act both as an initial resource provider and then as a converter in students' development of science-related capabilities. Using Bourdieu's key concepts of habitus, capital and field, we argue that the first role of outside-school factors is in providing an initial science-related resource set to students. Because key concepts of Bourdieu remain focused on social reproduction rather than social change (Calhoun et al., 1993) and pre-reflective features of action (Sayer, 2004), their use in understanding how outside-school factors may change science-related decisions and aspirations may be limited. This is where Sen's capability approach becomes useful. Making use of Sen's framework, we link the initial set of resources and the field in which these resources are realised to developed capabilities and functionings. We propose that the second role of outside-school factors is the conversion of initial resources to science-related capabilities. In addition, following Sen (1993), we highlight the distinction between science-related functionings (outcomes achieved by individuals) and science-related capabilities (ability to achieve desired functionings), and demonstrate why this distinction may be significant, especially for policy purposes.

We then examine whether our theoretical model helps us better understand students' science participation by using data on Turkish children learning science in England. In particular, we explore the formation and expansion of science-related capabilities ${ }^{1}$ in three

\footnotetext{
${ }^{1}$ While our interest in this study is science-related capabilities in general, we realise that for a student in full-time schooling, much of the conception of science drives from experiences of school science.
} 
Turkish students studying in London, and the role of outside-school factors in influencing this process.

This paper provides four main contributions to the science education literature. First, by making use of and integrating two frameworks, each of which has received relatively limited attention in the science education literature, we provide a novel theoretical model to explain students' science-related capability development. Secondly, our model highlights the twofold role of outside-school factors and explains the mechanisms through which these factors can provide initial resources and then help convert these resources to science-related capabilities. Thirdly, our two-stage model, which distinguishes between resources and conversion factors, and between capability development and functioning development in science, can help better align what society wants to achieve with science education with what is observed or measured in terms of science outcomes. Finally, by comparing and contrasting sciencerelated capability development in three students, we empirically demonstrate how our model can be useful in enriching understanding of the role of outside-school factors in science education.

\section{The Role of Outside-School Factors in Science Education}

A large body of research suggests that families play an important role in influencing students' interest, engagement, aspirations, and attainment in science (Ferry et al., 2000; Gilmartin et al., 2006; Huang et al., 2000; Mujtaba \& Reiss, 2014), and this relationship is subtle and complex (Atherton et al., 2009). Aschbacher, Li and Roth (2010) found that family socioeconomic status and having family members in science-related careers have a significant impact on students' science experiences, science-related career plans and persistence in science. Parental attitudes and support is also highly influential on the formation of post-16 science-related choices (Cleaves, 2005; Gilbert \& Calvert, 2003) and on career aspirations and academic development in science (Ferry et al., 2000; Reiss, 2004). This effect may depend on students' gender (Tenenbaum \& Leaper, 2003), where parental encouragement and support can strongly influence girls' perception of science- and mathematics-related career choices as suitable for them (Turner et al., 2004). Archer et al. $(2012,2013)$ argue that family resources, values and practices may have a significant influence on children's development of science aspirations. Similarly, DeWitt et al. (2011) found that children's perceptions of their parents' attitudes towards science have a strong relationship to the children's aspirations in science.

A related factor which influences students' science attitudes and aspirations is social class (Reay, David, \& Ball, 2005; Adamuti-Trache \& Andres, 2008). Working-class children between the ages of 10-13 are found to be much less likely to have science career aspirations (Archer, Dewitt, \& Wong, 2013) than middle-class children. Working-class girls and boys tend to associate science-careers with 'middle-class academic masculinity' (Archer, Dewitt, Osborne, et al., 2013; Archer et al. 2014), discouraging them from aspiring in science. Class may also influence access to valuable out-of-school experiences (Dawson, 2014b). Most visitors to science museums in the US are middle-class white students and their parents (National Research Council, 2009). Even when they visit, working class families may perceive exclusion from such informal science learning environments (Dawson, 2014b) or experience linguistic or cultural problems (Ash, 2004; Rahm, 2008) in these settings. From a social-cultural perspective, contemporary science could easily be viewed as a white middleclass dominant subculture (Lemke, 2001), and those outside it, such as minority students, may feel left out and develop their own common codes and communications in science learning (Lee \& Fradd, 1998; Rosebery et al., 1992). 
Ethnicity has also been suggested as a potentially significant element in influencing science outcomes (Huang et al., 2000; Riegle-Crumb, Moore, \& Ramos-Wada, 2011). For example, in the UK, Asian students' high achievement and high interest in science is well documented (Abbas, 2004). At the same time, while students of Indian and Chinese origin show both high aspirations and high achievement in science, this is not the case for students of Pakistani/Bangladeshi heritage as their progression and attainment has often been low despite expressing high aspirations (Elias et al., 2006). Similarly, in the USA, Gilmartin et al. (2006) found that family influence may work in different ways for different ethnic groups, with stronger and clearer, positive messages in Latino and Asian families as compared to White and African American families. Also, Asian American parents demonstrate high expectations and provide support for STEM careers as they see these as tools to gain access to status, income, stability, and success (Aschbacher, Li \& Roth, 2010).

Finally, even within science, there may be significant patterns and variations with regards to students' career aspirations. Gilmartin et al. (2006), for example, found that Indian and Pakistani students in the UK choose more applied professions and careers in science (e.g., medicine, pharmacy) rather than pure science (e.g., physics, chemistry) because their family members value these applied professions.

\section{Introduction to Theoretical Framework}

This study is based on two sociologically-informed theoretical foundations: Pierre Bourdieu's Habitus, cultural and social capital and field and Amartya Sen's Capability Approach. Although these frameworks have been used extensively by education researchers, their use has been quite limited in science education. There are only a few papers that employ Bourdieu's work in science education (notably Adamuti-Trache \& Andres, 2008; Archer et al., 2012; Wong, 2012), and we believe this paper is the first one that uses Sen's Capability Approach in science education.

\section{Habitus, Cultural Capital and Field}

Habitus is a critical and complex concept in Bourdieu's work which explains how individuals' social actions, practices and dispositions are formed and affected by their social world and specific experiences (Bourdieu, 1977). Habitus, which can be conceptualised as the internalisation of the social structure, creates one's worldview and acts as a guide for an individual's life (Dumais, 2002). Habitus is formed, realised and first transmitted at home during primary socialisation (Swartz, 1996).

Although some critics have argued that there is inherent determinism in habitus and its use in education research should be very limited (Tooley \& Darby, 1998), others have pointed out its useful function in mediating between various dichotomies such as structure and agency, and the social and the individual (Maton, 2012; Nash, 1999). Habitus generates a scheme that is embodied in individuals through their socialisation and social interactions. This scheme consists of beliefs and dispositions that are the results of childhood experiences, and individual and family history as well as cultural codes. That is, "the structural code of the culture is inscribed as the habitus and generates the production of social practice" (Nash, 1999, p.177). Habitus can play both a transformative and a constraining role in producing a wide set of actions, so although it allows for individual agency, it may also bias individuals to act in certain ways (Reay, 2004).

Bourdieu (2008) argued that there is a strong connection between owning different kinds of capital, a class-specific habitus and the choices individuals have. The formation of habitus depends on the availability of different kinds of capital and these capitals are characterised by 
Bourdieu (1986) as being of three major forms. Economic capital is in monetary or material form, representing financial resources, and is critical in reproducing social advantage and disadvantage. Social capital includes both material and non-material resources that one possesses through a network of connections one can effectively mobilise. Finally, cultural capital is gained mostly through social learning and constitutes people's symbolic and informational resources for action.

Cultural capital is the valued knowledge that exists in three forms: (i) it can be objectified, that is materially represented in things such as books, museums, art works, etc.; (ii) it can be embodied, that is in predispositions such as skills, body language, etc.; and (iii) it can be institutionalised such as in educational degrees and certificates (Bourdieu, 1986). Cultural capital is partially formed by formal education, but it captures more than that. It includes different cultural skills - most individual action is determined by cultural capital - and it depends heavily on "total, early, imperceptible learning, performed within the family from the earliest days of life" (Bourdieu, 1984, p.66). Social capital, on the other hand, is at the inter-individual level, which involves social relationships that are directly usable in the short or long term. A key feature of social capital is that it transforms contingent relationships (e.g., those at the neighbourhood, the workplace, kinship) into durable relationships that are both necessary and elective at the same time (Bourdieu, 2002).

The third concept that we focus on, which is also highly related to habitus and cultural and social capital, is field. Field provides the context in which the potentialities of the habitus are activated (Bourdieu \& Waquant, 1992). In addition, various capitals are invested and their values are realised in a field whose structure is the source of the specific effects of capital (Bourdieu, 2002). Consequently, individuals with similar habitus or cultural and social capital can demonstrate very different practices or positions if there is variation in their fields (Bourdieu, 1990). A field can be, for example, a higher education institution, a family, a town, a profession, and each field develops a distinct logic of its own, a natural understanding of the world and implicit and explicit rules of behaviour.

Field is like a game with rules. Individuals may have different capitals with which to play; they may vary in their understanding of the rules of the game and in their dispositions (Bourdieu \& Wacquant, 1992; Reay et al., 2008). Field's effect on habitus is twofold. First, the effect can be characterised as conditioning, that is, the field structures the habitus which "is the product of the embodiment of the immanent necessity of the field" (Bourdieu \& Wacquant, 1989 p.44). Secondly, the relationship can be viewed as one of knowledge and cognitive construction, that is "habitus contributes to constituting the field as a meaningful world, a world endowed with sense or with value, in which it is worth investing one's energy" (Bourdieu, in Wacquant, 1989, p.44).

\section{Capability Approach}

Amartya Sen $(1997,1999)$ defines capabilities as what people are actually able to do and to be. The basic reasoning behind this approach is that it is not sufficient for individuals to have resources or the end product of these resources (e.g., income, status, money), but they should be able to develop their capabilities, and this ability and freedom is the key to wellbeing (Nussbaum, 2000; Sen, 1999). The capability approach is an interdisciplinary framework to study and evaluate human wellbeing. The appealing characteristic of the capability approach is that it takes a multidimensional view of human wellbeing, and primarily focuses on human capabilities, which are defined as "a person's ability to do valuable acts or reach valuable states of being; [it] represents the alternative combinations of things a person is able to do or be" (Sen, 1993, p.30). The capability approach makes a clear distinction between outcomes 
(achievements) and freedom to choose. It is the freedom to choose, and the potential and opportunity to achieve a desired outcome, that matters in the capability approach.

A central concept in this framework is functionings, valued outcomes that are achieved by individuals. A functioning is "an achievement of a person, what she or he manages to do or to be" (Sen, 1985, p.10). Functionings may range from basic ones, such as being adequately nourished, healthy and literate, through common ones such as working or resting, to more complex ones such as being able to take part in the life of the community and having selfrespect (Sen, 1999). Capability, on the other hand, is the ability to achieve desired functionings. A person's 'capability' refers to the alternative combinations of functionings that are feasible for her $^{2}$ to achieve. Capabilities are "a kind of freedom: the substantive freedom to achieve alternative functioning combinations" (Sen, 1999, p.75). Sen gives the example of fasting in this context. A wealthy person who is fasting and a poor person who does not have food to eat may have the same functioning achievement, but their capability sets differ substantially. While the first one can choose to eat well and be well nourished, the second one cannot (Sen, 1999, p.75). The capability approach suggests that we should not simply look at the functionings of individuals; rather, we should focus on the freedom and opportunities available to each individual so that they achieve what they value.

Sen argues that people should be in charge of their own wellbeing and they should themselves decide on how to use their capabilities (Sen 1999). Because actual capabilities critically depend on the nature of social arrangements, both individuals' agency and their freedom in exercising this agency are notable in capability approach.

Sen's capability approach also highlights conversion factors. These translate an individual's resources into valued functionings (Sen, 1992). The importance of the conversion factors is that they take into account diversity and individual circumstances. Sen (1999) also suggests that there may be systematic variation in conversion of incomes into distinct functionings because of different types of contingencies.

Research that incorporates the capability approach in education has examined issues such as gender and equality (Unterhalter, 2007), disability and special needs education (Terzi, 2005) and higher education and participation (Watts \& Bridges, 2006). Capability approach can be particularly useful in assessment and evaluation. Instead of focusing on outcomes (e.g., examination results), desire satisfaction or resource allocation (e.g., spending per student), focusing on actual educational choices and available freedoms to pursue one's valuable and meaningful goals could be a better option (Unterhalter, 2003), as similar functionings may mask very different capability sets (Walker \& Unterhalter, 2007).

While Sen's capability approach has not been applied directly in the science education literature, the emphasis on freedom and choice is not entirely new. For example, Falk and Dierking (2000) introduced their 'Contextual model of learning' as a theoretical construct for investigating learning within free-choice settings (e.g., in museums). Learning is conceptualised as a contextually driven effort to make meaning, which is a process/product of the interactions between an individual's personal, sociocultural and physical contexts over time. Therefore, for example, depending upon who the visitor is, what they know, why they come, and what they actually see and do, the outcomes of the museum experience could be dramatically affected (Falk \& Storksdieck, 2005). Our study also highlights free choice and outside-school settings, and the role of contextual factors in science education, but by incorporating Sen's capability approach, we hope to introduce a more granular view of outside-school factors that may act as conversion factors in science-related capability and functioning development.

${ }^{2}$ In places, to avoid circumlocutions, 'she' and 'her' are used whether an individual is male or female. 


\section{Theoretical Model: Combining Bourdieu and Sen}

In this two-stage model, we first identify habitus, cultural and social capital and field as Bourdieu's key ideas to help conceptualise how science-related resources and capitals are formed outside the school. In the second stage, these resources are turned into science-related capabilities. These science-related capabilities can then be turned into science-related functionings that result in attitude, aspiration and attainment formation. We outline the basic model in Figure 1.

\section{Insert Figure 1 about here}

A small number of previous studies make use of and combine the perspectives of Bourdieu and Sen. In a policy-oriented paper, Schuller et al. (2004) suggest that human, social and identity capitals comprise capability-based assets; these are linked to Sen's capability framework, and they can be mobilised to yield returns. Abel and Frohlich (2012) build on Bourdieu's different forms of capitals and habitus to explain how the unequal distribution of resources could lead to reproduction of unequal life chances and health inequalities. Pointing out the limitations of habitus in explaining the role of agency, they propose Amartya Sen's capability approach as a very useful link between capital interaction theory and public health action to reduce health inequalities. Although their paper is on medical sociology and the main question is how to reduce health inequalities, Abel and Frohlich (2012) provide a detailed discussion as to why a capital-based explanation is limited and how Sen's capability approach could be positioned in a structure-agency perspective to address the main principles of health promotion. Finally, Hart (2012) blends Sen's capability approach and Bourdieu's concepts to explore the development of aspirations and capabilities. She suggests that commodification of individual capital could lead to individual capability through conversion factors. While Hart (2012) studies aspirations with a focus on education policy and social justice implications, we examine the formation of three elements with regards to science: students' science attitudes/interests, their science aspirations and their science attainment. Because our main research question is about the mechanisms and factors outside the school that influence students' science attitudes, aspirations and attainment formation, our model explains how various outside-school factors (i) help form the habitus and capital, and act as a field, and then (ii) help convert capitals to science-related capabilities.

\section{Discussion of the Model}

Our model starts with Bourdieu's cultural and social capital, and habitus. The value of the capital is determined and habitus is recognised in a specific field. It is the interaction of habitus, cultural capital and field that produces the logic of practice (Bourdieu, 1990; Reay 2004). In fact, Bourdieu was quite specific in relating habitus, capital, field and practice, suggesting: $($ Habitus $\times$ Capital $)+$ Field $=$ Practice $($ Bourdieu, 1984, p.101). Translating this to our model, we argue that for each child, her parents, family and socio-cultural environment provide an initial habitus and capital related to science. Her science-related habitus and cultural and social capital are formed mainly in the family through social relationships, but the parents and the child probably do not even know or realise how this actually occurs, as habitus and cultural and social capital operate in less than a conscious manner (Bourdieu, 1990; Farnell, 2000). Our understanding of science-related habitus and cultural and social capital is somewhat similar to Archer et al.'s (2012) conceptualisation of family habitus in 
their study of students' science aspirations. That is, we also want to examine "the extent to which the everyday family 'landscape' shapes, constrains, or facilitates aspirations and engagement in science through the combination of attitudes, values, practices, and ways of being that they engage in" (Archer et al., 2012, p.886). Our main departure is that, while Archer et al. (2012) consider family habitus as an all-encompassing term including family resources, practices, values, cultural discourses and identifications, we want to develop a more granular view by employing Bourdieu's distinct but related terms of habitus, cultural and social capital and field and combine this with Sen's capability approach to characterise and examine out-of-school factors.

Our conceptualisation using a Bourdieuian lens helps us better comprehend sciencerelated capitals beyond the well-studied views of family socio-economic status, ethnicity or cultural background. First, a family's socio-economic status could be a factor affecting their children's initial science-related capital (Aschbacher et al., 2009). Without realising it or making any conscious effort, a relatively wealthy and better educated family could have a better understanding and use of science-related concepts; they may be better at explaining science-related phenomena and answering their children's science-related questions, or simply have a better network and access to people doing careers in science (doctors, scientists, etc.). But socio-economic status (SES) alone cannot explain the formation of this initial science-related capital. It is quite possible that a lower SES family provides a higher science-related capital to their children, perhaps because of their personal interest, attitude, etc. (Cleaves, 2005; Gilbert \& Calvert, 2003), than a higher SES family with very limited interest and relationship to science. A second important factor affecting the initial sciencerelated capital is cultural and ethnic background. For example, within certain cultural contexts and ethnic backgrounds, science and scientists may be regarded more highly than they are within other cultural contexts and ethnic backgrounds (Gilmartin et al., 2006; Huang et al, 2000). It may also be the case that individuals from certain religious or other cultural backgrounds may be more or less open and enthusiastic than others in talking about sciencerelated concepts (Sjøberg \& Schreiner, 2005). Finally, independent of the previous factors, and again possibly without realising it, some families may provide a higher science-related capital to their children because of higher personal interest in science (e.g., one or more parents' special interest in science), a science-related job (e.g., a scientist sibling), a role model in science (e.g., a family friend who is a doctor), etc.

In understanding the role of outside-school factors in science education, Bourdieu's framework is not only useful for our conceptualisation of science-related resources, but also for access, inclusion and equity issues. Bourdieu's (1986) discussion of transmission, accumulation and conversion of various forms of capital helps us understand reproduction of inequalities in science education. First, different forms of capital are transmitted to children from their parents. These can include simple inheritance of economic capital to more nuanced inheritance of cultural capital, practices and dispositions such as enjoyment of museum visits or science reading that can provide an advantage or disadvantage to children. Secondly, different forms of capital can be accrued; indeed, habitus is the embodiment of the accumulation of value given by the volume and composition of the different forms of capital (Skeggs, 2004). But, there may be subtle differences between parents' social positioning and dispositions towards education (i.e., family habitus), and they may also differ in the possession and desire to activate capitals (Vincent et al., 2012). Thirdly, considering conversion of different forms of capital to one another, consciously or unconsciously (Bourdieu, 1986), accumulation will have exchange value too (Skeggs, 2004). For example, middle or upper class parents using economic capital to buy science-related gifts or providing their children with private education convert economic capital to cultural or science-related capital, which in turn will have exchange value and provide advantages in later life such as 
employability and social networks (Skeggs, 2004). In creating and exchanging various forms of capital, different people may not be able to use or exchange various forms of capital in certain settings. As Skeggs (2004) points out, culture "can be used by the middle class as a resource to increase exchange value, establishing relations of entitlement, but that same culture cannot be converted for the working class" (p.173). The middle class has access to other (e.g., working class, ethnic minority) cultures as a resource in their own self-making (Skeggs, 2004); they can enrich themselves through the consumption of ethnic diversity (Hage, 1998), and acquire valuable multicultural capital (Gibbons, 2002), whereas others who do not possess the dominant cultural capital may face exclusion, or even exploitation, with their values proving to be "use-less" (Skeggs, 2004, p.176) and with the risk of becoming residualised and positioned as excessive in the process of generating use and exchange value if they are perceived to not share white middle class values (Reay et al., 2007).

In addition, in many outside-school science learning contexts such as science centres and museums, knowledge that counts and culture that dominates may lead to reproduction of inequalities through symbolic violence (Bourdieu, 1990), which results in non-dominant group members (ethnic minorities, working class individuals, etc.) being at a significant disadvantage. For example, low-income minority ethnic individuals of a mix of ages and genders have been found to experience exclusion from informal science education settings (Dawson, 2014a).

While a Bourdieuian perspective is very useful for explaining students' science-related, outside-school resources and potential reproduction of inequalities in accessing these resources, Bourdieu's focus is more on social reproduction than social change (Calhoun et al. 1993), with an emphasis on pre-reflective dimensions of action (Reay, 2004; Sayer, 2004). We therefore don't receive full theoretical guidance from this perspective on how to change structurally-based dispositions and attitudes about science. In addition, considering Hays' (1994) distinction between structurally reproductive agency and structurally transformative agency, Bourdieu's discussion of agency is closer to the former, which can help us explain potential structural factors that might limit students' access or gained benefit from certain outside-school science resources, which then reproduce inequalities. However, in addition to this, we are also interested in understanding the role of structurally transformative agency in forming and modifying science attitudes, aspirations and attainment. Therefore, we need a complementary theoretical framework. Furthermore, while field provides the social contexts, there is little focus in Bourdieu on the internal content of a given field (Naidoo, 2004), which limits its use in our focus on specific outside-school factors related to science. Similarly, Bourdieu's family is functional and static (Silva, 2005) in that the process through which cultural capital is diffused and transformed is not clear: "Cultural capital's diffuse and continuous transformation within the family escapes observation and control" (Bourdieu, 2002 p.92).

In light of the above points, we next turn to Sen's capability approach which provides a helpful lens and a complementary framework in our study of outside-school factors in science education. In continuing to build our model, we synthesise Sen's critical concepts with Bourdieu's perspective, and discuss how the two approaches can enrich each other.

As an economic theory in origin with a contrasting view to existing resource-based and utilitarian approaches, Sen's capability approach does not primarily focus on resources. Instead, he prioritises capabilities, and calls those resources that are converted to capabilities commodities (Sen, 1999), seemingly with an economic undertone. A Bourdieuan view enriches this perspective by highlighting economic, social and cultural capitals, and their conversion and interactions in various fields. That is, the initial science-related resources and habitus with which a student is endowed are more than an economic commodity; rather, they 
are a consequence of all science-related social interactions and reproductions in the first place.

Sen's capability framework helps us distinguish between science-related resources (commodities), science capabilities and science functionings. While we acknowledge the dynamic nature of the relationships between these stages in practice (e.g., capabilities enhancing resources, or functionings helping develop certain capabilities), our model can be viewed more as a time-based explanation of capability and functioning development, such that a child may have an initial endowment of science-related capital which is acquired naturally from her family environment and socio-cultural context, for example before she reaches school age. This may then be converted into developed science capabilities or not, based on the existence of conversion factors which depend on the interplay between agency (deliberate specific acts such as buying science gifts) and structure (habitus, capital and field). In characterising conversion factors, structure is not necessarily static as various forms of capital can be exchanged with a use value which can provide further advantages or disadvantages to students coming from certain class or ethnic backgrounds (Bourdieu, 1986; Skeggs, 2004). However, it is not just structure and associated exchange value or use value of capitals that drive conversion factors as agency takes a more central stage in forming Sen's conversion factors, which are also affected by personal (e.g., physical condition, intelligence), social (e.g., norms, gender roles, societal hierarchies) and environmental (e.g., infrastructure, institutions, public goods) characteristics (Robeyns, 2005).

Our conceptualisation of initial science-related capital is slightly different from 'science capital' introduced by Archer et al. (2014, 2015). In our model, initial science-related capital is provided to a child mostly at a pre-reflexive level which is then transformed into capabilities and functionings through conversion factors; Archer et al.'s conceptualisation seems to include dispositions as well as activities and deliberate actions.

We suggest that there may be certain practices and actions outside the school that act as conversion factors of initial science-related resources to science-related capabilities. For example, parents, through conscious actions and purposeful efforts, can help their children develop science-related capabilities. For instance, parents may participate in science-related activities such as taking their children to visit science museums or working together on a science project or homework; they may buy science-related gifts, toys or magazines for their children, or simply raise their science-related awareness in daily activities or conversation.

However, science-related capability development is not a straightforward process. Although agency can help develop science-related capabilities, these are not independent of structural characteristics, inequalities and the associated reproduction process (Bourdieu \& Passeron, 1990). First, the existence of certain conversion factors (and related actions) may entirely depend on a certain type of capital. For example, with limited economic capital, a parent may find it an unnecessary luxury to subscribe to a children's science magazine or may not be able, due to work demands, to join a children's weekend science fair. Similarly, even if they have the personal interest, an immigrant parent with limited English language skills may not get into science-related conversations with her children whose science terminology is entirely in English. Secondly, even if the conversion factor exists and related actions takes place, the benefit that may be received from it and the subsequent capability development may be significantly inhibited as a result of habitus and cultural and social capital. For example, even when economic capital is not an issue, individuals from minority ethnic backgrounds may get a 'not for us' feeling on museum or science centre visits (Dawson, 2014a). Finally, considering the significance of field in converting science-related resources to capabilities, certain families can provide a more conducive field for their children to develop science-related capabilities (e.g., private schooling, living in a well-off neighbourhood with many people in science careers), whereas some students may experience 
fields that are highly unfavourable for science learning (e.g., a girl living in a family in which science careers are only associated with men). To sum up, because the capability approach largely focuses on the individual, her freedom and choices, and there is not much mention of social structures (Stewart, 2005), its reach and significance can be substantially improved by incorporating Bourdieu's emphasis on habitus, cultural and social capital and field.

Next, it is important to remember Sen's distinction between capabilities and functionings. A child, for example, may develop certain science-related capabilities, but these may not necessarily translate into science-related functionings. A student may develop an excellent set of science-related capabilities, but with her freedom and meaningful reflection, she may decide not to convert these capabilities to functionings. In our model (Figure 1), sciencerelated functionings have three dimensions: science attitude/interest, science aspirations and science attainment. An important aspect of our model is that there are certain factors that help convert science-related capabilities to science-related functionings. These may include efforts to make science-related careers appealing, showing good role models in science, demonstrating the exciting, and relevant side of science, etc. Thus, we propose that there are two types of conversion factors. The first set of factors convert initial science-related capital to science-related capabilities, whereas the second convert science-related capabilities to science-related functionings.

\section{A Case Study of Turkish Immigrant Students in London Study Background}

In light of our theoretical model, we next analyse the two-step science-related capability and functioning development of three Turkish-British students. All three students come from very similar socio-economic backgrounds and attend the same full time Turkish independent school in London. Of the three students, Zeki ${ }^{3}$ (male) and Fulya (female) are in Year 7, and Derya (female) is in Year 10. Fulya and Derya are sisters. We selected students from Year 7 and Year 10 as most of the previous research suggests that aspiration and interest in science at the beginning of the secondary school is still high, but starts to decline afterwards (Archer et al., 2013). Using a combination of in-class observations, detailed questionnaires and student and parent interviews, we were able to provide a rich picture of each student in terms of their formation of an initial set of science-related resources, conversion of these resources into science-related capabilities and, finally, conversion of these science-related capabilities into science-related functionings in the form of attitudes, aspirations and attainment.

We started our study with in-class observations (3 x 50 min lesson for each student). During the in-class observations, we were able to observe whether each of Zeki, Fulya and Derya showed a genuine interest during the science lessons, and how attentive they were. Although the focus of our study is on outside-school factors, these in-class observations helped us prepare for subsequent surveys and interviews with the students, and also enabled us to verify some of their responses and comments.

Next, we prepared a detailed questionnaire which look at students' interest in science in general and in school science, their career aspirations, their perception of image of scientists, parental interest in science and parental promotion and activities in science, and their engagement with science outside-school with related demographic, socioeconomic and cultural dimensions of their family. In developing the survey instrument, we decided to build on previously developed and validated instruments, and used constructs that have well established theoretical and empirical validity (notably, Gilmartin et al., 2006; DeWitt et al, 2011; Weinburgh \& Steele, 200; Glynn \& Koballa, 2006; Gibson \& Chase, 2002). We

${ }^{3}$ All names in this paper, including students and their parents, are pseudonyms. 
analysed each of the three students' questionnaire responses, and compared them not only with the responses of the other two but also with the responses of the other students in their classes.

Following in-class observations and questionnaires, we then conducted interviews with the three students and, separately, with their parents. Student interviews were carried out in an available room in the school. The interviews were one-to-one and semi-structured. Each interview lasted about 30-45 minutes, and was audio-recorded with the permission of each student and their parents. We started student interviews with general questions such as their likes and dislikes in and out of school, and then we probed the factors that might affect their science attitudes and career aspirations, such as the availability of science-related resources at home and in their social network, role model visibility and their perceptions of their parents' attitudes to science and their education overall. Students were in general very attentive and talkative, and able to give vivid examples from their daily lives. After completing the interviews, they were transcribed verbatim using pseudonyms.

For the parent interviews, much the same approach was followed. Parent interviews were usually longer than student interviews (about 45-60 min) and they were carried out at their homes. One advantage of conducting interviews at home was that parents were comfortable during the interviews, and seemed very open and genuine in their responses. We only interviewed the mothers as fathers were reported to be busy at work. Also, when parents were asked for an interview, fathers proposed mothers to be interviewees. Interviews were undertaken in English or Turkish, depending on which the interviewee preferred.

The interviews were analysed as follows. First, data were coded by focusing on emerging concepts and common themes in an iterative way (Miles \& Huberman, 1994) with the constant comparative technique (Glaser \& Strauss, 1967; Corbin \& Strauss, 2008). In this technique, by comparing emerging indicators with previously identified ones within and across interviews, the goal is to "discern conceptual similarities, to refine the discriminative power of categories, and to discover patterns" (Tesch, 1990, p.96). Unlike grounded theory approaches, our goal with this analysis was not to generate new theory, but rather systematically to compare our codes and iteratively identify emerging themes which then formed the basis of our subsequent analysis, based on our theoretical framework.

Using the constant comparative technique, we first compared emerging concepts and corresponding codes within each interview, between student interviews, between student and family interviews, and between family interviews. After identifying key patterns and emerging themes related to outside-school factors and students' science participation in interviews, we then linked these themes with corresponding concepts of resources, conversion factors, capabilities and functionings in our theoretical framework.

In performing our qualitative analyses, we did not use software such as NVivo. This is because the data we collected were quite manageable in terms of size and complexity. Also, considering the criticisms related to the use of software in such qualitative work including the potential to creating distance, marginalising reflection and alienating the researcher from data (Kelle, 1995; Richard \& Richard, 1991; Morison \& Moir, 1998), and the difficulty of reconciling ICT with interpretive and creative stages of qualitative analysis (Roberts \& Wilson, 2002), we preferred to carry out coding and analyses manually.

\section{Zeki, Fulya and Derya}

We selected our three students for the following reasons: First of all, they all come from low socio-economic background immigrant parents, which potentially suggests a low level of initial resource set available for them. Secondly, Fulya and Derya are top-set students, and they seem to demonstrate a high level of science-related capability development, whereas 
Zeki is an upper middle set student in school, but with low levels of science-related capability development. Thirdly, although both Fulya and Derya show a high level of attainment and interest in science, Derya has high career aspirations in science whereas Fulya shows little interest in a science career (see Table 1 for an overview).

Insert Table 1 about here

Because these students seem quite similar in terms of initial resources, but widely different in their science-related capabilities and functionings, they are ideal candidates for exploring the conversion process further with the lens of our theoretical framework. In addition, all students in this case study are from the same school, which suggests that their school factors are similar.

\section{The Case of Zeki and his Parents}

The parents of Zeki have been living in England for eight years. They moved to England from a small village in Sakarya, Turkey. Zeki's mother, Nihal, is a primary school graduate and his father is a high school graduate. Nihal works part time as a curtain tailor in her husband's small curtain tailoring business and part time as a housewife. They live in a council flat in north London.

Zeki's parents are supportive of his education; however, it appears that their support does not go beyond general and broad advice. His parents try to monitor Zeki's school work and educational development, but this control appears to be somewhat distant. For example, when asked about any engagement with Zeki's school work or projects in science, his mother Nihal indicated that she was never involved in his science-related school work or projects. Zeki and his parents seem not to share or engage much in terms of science-related learning, discussion of school or everyday topics or activities related to science. Nihal mentions language as a barrier on this as her English skills are quite poor, and she always communicates with her children in Turkish. However, while Zeki can speak both Turkish and English, when it comes to school or science-related topics, he speaks in English and he can hardly speak about such subjects in Turkish. As a result, Nihal says that although Zeki sometimes tries to start science-related conversations with her, after a few attempts he gives up. In another example, Nihal mentioned an occasion at school in which she saw Zeki's name on the board as being successful, and asked what this was about. Nihal says that Zeki tried to explain her what they did in the lesson, but he struggled to explain it in Turkish. At this point, the interviewer asked Nihal what was it about, and she could barely say "it was something related to science lesson, and Zeki came first". One point to emphasise is that this is a Turkish school, so most teachers are bilingual; therefore, information flow between parents who can only speak Turkish and the school should not be an issue. So, with some additional effort, Nihal could have learned from the teachers what Zeki's real achievement was. Finally, regarding Zeki's career aspirations and what his parents wish him to do in the future, his mother indicated that although she is not particularly interested in science, she "always admires doctors" and would like Zeki to become a doctor; she also says she would love to see Zeki as a pilot. However, Zeki is not keen on either of these possibilities.

While Zeki is among the high achieving students at school, science is not one of his favourite subjects. From the interview, and from his highly positive responses to survey questions about school science and science lessons (e.g., "I would like to study more science in the future", "I do well in science", "I learn things quickly in my science lessons"), it is 
clear that Zeki does quite well in school science, and likes studying science at school. However, he does not have much interest in science beyond the classroom, saying "I do not usually use science". When Zeki was asked if he ever participated in a science project, he said "yeah", but "cannot remember what was it about, as it was years ago". Zeki also said he did not get any help from his parents; he received help "just from friends". Finally, Zeki does not have any aspirations in science or for a science-related career (he wants to be a businessman or a professional football player), nor does he have any science-related role models. He is also not involved in any science-related, outside-school activities.

\section{The Case of Fulya, Derya and their Parents}

The parents of Derya and Fulya have been living in England for 17 years. They moved to England from a small Turkish village in Greece. As with Zeki's parents, the mother, Gonca, is a primary school graduate, and the father is a high school graduate. Gonca is a housewife and the father operates a coffee shop, and they too live in a council flat in north London. Overall, both parents come from a low socio-economic background, which is quite typical for the Turkish immigrant community in England.

Derya's and Fulya's parents appear to be highly supportive of their daughters' education, but, unlike the parents of Zeki, they demonstrate high engagement with their education. Despite being only a primary school graduate herself, Gonca shows a genuine interest in the science-related topics that her daughters talk about. Both Fulya and Derya enjoy having conversations with their parents about new and interesting things that they learn in science, and their parents appear to enjoy this too. For example, when asked about details of sciencerelated conversations with her daughters, Gonca recalls specific topics and gives examples, such as "the movement of atoms" and "the growth of animals". When Derya was asked about her favourite science topic in a separate interview, her response was "atoms and molecules". As is the case for Zeki's mother, Gonca cannot speak English. But both Derya and Fulya are confident in Turkish, and also feel comfortable translating science-related concepts for their mother from English to Turkish. As a result, they do have many science and school-related conversations with their parents. Their parents also appear quite dedicated in support of their daughters' science education. For example, when there were logistical problems in Derya's participation in an international science competition in the Netherlands due to last minute trip-organising issues with her school, her father took two days off work and drove her from England to the Netherlands just to make sure she did not miss the competition. Overall, both Fulya and Derya appear to be developing very high science-related capabilities.

\section{The Case of Fulya}

Science is one of the subjects Fulya likes the most, along with English and mathematics. She likes all the subjects within science but physics is her favourite. She also remembers and explains the two science lessons this year she enjoyed the most, where they did experiments and made posters. Although she says she does not use science in her daily life much, she thinks she will use it more as she grows up. Fulya participated in a major science project in 2013 (the World Challenge project), in which she got a certificate, and she says she enjoyed the process and it helped her in terms of learning.

Fulya wants to be a lawyer, and this is not because of any role models or people she knows, but because she thinks "this job is best" for her. An interesting observation is that she says that previously she was thinking about being a doctor, but as her English has improved she now wants be a lawyer. Fulya considers her elder sister and her parents as role models, saying "if I work like them, whatever I do, I will be good at the end". She does not watch 
much TV, though she likes watching scientific and historical documentaries. Fulya also makes an interesting comment about visiting a science museum with school versus with her parents. She says she enjoyed and learned more when she visited with her parents as she says "with parents I am more relaxed, I take my time, and do not need to rush".

\section{The Case of Derya}

Derya's two favourite subjects at school are science and mathematics. She likes a variety of topics in science, and her favourites are those related to atoms. She is not too excited about experiments, as she thinks some of them are repetitive, which makes them boring. She particularly likes numbers-related work in science, and "when numbers disappear, like in biology, then it makes science difficult for me, when there is lots of words and memorising". She also finds science very relevant, and she thinks she uses science quite often in her life.

Derya makes an important observation regarding the role of science in making sense of and understanding the world, and gives an example of how her science lessons "helped her understand how it is raining". As a top set student, she also participated in two international science-related contests: Genius Olympiad in the USA and Unesco Olympiad in the Netherlands. She finds being in competitions were very helpful in terms of learning, and says "she learns also a lot about other projects". When she is asked about whether she enjoyed preparing for and being at the competition, she replies "yes, I think the most important thing was we had a lot fun, it was really fun because we had loads of exciting activities". That is, she seems to enjoy the entire process of preparation and competition in science. She aspires to study medicine and become "either a physiotherapist or a heart surgeon or some kind of surgeon". Finally, Derya mentions the role of her family, saying "I have a lot of family support"; while they are not involved in her homework (except her mother's help with mathematics), they always support and encourage her, and the fact that her father took her to the Unesco Olympiad in the Netherlands and supported her there was very special to her.

\section{Discussion of the Three Cases in the Light of the Theoretical Model}

The three main components of our model in which outside-school factors play a significant role, are: (i) a student's initial science-related resource set; (ii) conversion of the student's initial science-related resources to science-related capabilities; and finally (iii) conversion of science-related capabilities to science-related functionings (Figure 1).

\section{Initial science-related resources}

Considering both the case of Zeki and the cases of Fulya and Derya, we see that the two families are very similar in terms of their cultural backgrounds, ethnic factors and socioeconomic status. So, at a first glance, one might think that both families are very similar in terms of the resources they provide to their children. However, when we take a habitus, cultural capital and field based viewpoint, and take into account the role of parental attitudes to science and interactions within the family, we observe that the parents of Fulya and Derya provide a higher set of science-related initial resources than do the parents of Zeki. The difference in parents' overall attitudes to science is clear both from the interviews and from the students' responses to questionnaires. For example, both Fulya and Derya 'strongly agreed' to statements in the survey such as: 'my parents think science is interesting' or 'my parents would be happy if I become a scientist one day', whereas Zeki's response to these questions were only 'agree' and 'neutral' respectively. Overall, we propose that, despite very similar socio-economic status and parental, ethnic and sociological backgrounds, Zeki's 
parents and Fulya's and Derya's parents are not identical with respect to the initial sciencerelated resources they provide to them. This is because of the difference in their attitudes to science. One benefit of our model is to make this difference evident. Using only common survey items on parental education and occupations or ascertaining students' family or ethnic backgrounds would give us only part of the whole picture regarding the role of parents in providing initial science-related resources.

\section{Conversion from Science-related Capital to Science-related Capabilies}

We suggest that certain parental actions and practices outside the school act as conversion factors in converting students' science-related resources into science-related capabilities. Indeed, in the case of Zeki, compared to Fulya and Derya, we observe major differences in the development of science capabilities. From the interviews, class observations and survey responses, Zeki appears to have low/moderate science capability. Although he is good at school science, he does not show any interest in science outside the school. His responses to the survey questions designed to get a sense of students' science-related capabilities (e.g., 'When I learn an interesting science topic, I can learn much more about it at home', and 'If I want, I can undertake an experiment during a science class to a high standard') were all neutral. Zeki's parents show no particular interest in science, and their encouragement and support in science is quite limited and articulated in very general terms. They do no sciencerelated activities with Zeki (in the survey Zeki's answers were 'no' to all eight questions on science-related activities with parents) and they don't have any conversations related to school science or any science-related topics in everyday life.

On the other hand, both Fulya and Derya appear to have very high science capabilities. They are both very comfortable and confident in science-related conversations, they show genuine interest in science and science-related topics inside and outside the classroom, and they both scored very highly on survey questions for science-related capabilities. In contrast to Zeki's parents, the parents of Fulya and Derya are very much engaged in their support and involvement in science. They have many lively conversations with their children related to science, are very committed and proactive in their support of their science activities and very genuine in their interest in science (they seemed to enjoy and remember many science-related conversations during the interview). In addition, survey responses of both Fulya and Derya indicate that their parents do many science-related activities together with them (their scores in this section are much higher than those of their class averages). Furthermore, in the interview, Fulya's and Derya's mother, Gonca, shared with us several other activities and actions that happen at home. For example, the parents buy books (science and others) for their daughters, and take them to science museums as a family. Also, Gonca says, quite proudly, "my daughters watch very little TV and, when they watch, they normally watch useful stuff".

To sum up, we observe a significant difference between Zeki compared to Fulya and Derya in their science-related capabilities, and we argue that this is primarily because of the major difference in their conversion factors (e.g., parental actions) from science-related resources to science-related capabilities. We propose that the parents of Fulya and Derya, through their meaningful and purposeful actions promoting and encouraging science, provide a set of notable conversion factors which result in their daughters developing a high level of science-related capability. In contrast, Zeki's parent do not provide such conversion factors, which limits the conversion of his science-related capital to science-related capability. 


\section{Conversion from Science-related Capabilities to Science-related Functioning}

Building on Sen's distinction between capability and functioning, we highlight the difference between science-related functionings (outcomes achieved by individuals) and science-related capabilities (ability to achieve desired functionings). As outlined in Figure 1, two different sets of conversion factors play a role in their development. The first set of conversion factors play a role in converting science-related initial resources into science-related capabilities as outlined in the previous section. A second set of conversion factors play a role in converting science-related capabilities to science-related functionings. We argue that what matters is for students to develop science-related capabilities, even if these do not translate into sciencerelated functionings. We suggest that there is nothing inappropriate if a student does to not choose a science career so long as she is well-informed about science and has developed science-related capabilities, but with her own free will decides to pursue something else.

While both Fulya and Derya demonstrate a high level of science-related capabilities as outlined above, Derya is very interested in science careers and wants to become a doctor, whereas Fulya has her passion in law, and wants to become a lawyer. Both Derya and Fulya do very well in science lessons, and enjoy doing science-related activities outside the school. They certainly both feel themselves capable of pursuing science careers. But with their own reflections, freedom and choice, they want, at least at this stage of their education, to pursue different careers. Our observation and conclusion is very much in line with Archer et al. (2014)'s work on adolescent boys' science aspirations which observes that some boys (i.e., "behaving/achieving" ones) do not aspire to careers in science despite having very good identification and attainment in science.

However, the case of Zeki is different. We do not observe any significant science-related functionings in Zeki both in terms of attitudes or aspirations. His attainment in science is quite high, but because of the lack of conversion factors (at both the first and second stage), he does not show much science-related capability or functioning development.

\section{Conclusions}

From home environment and parents' socio-economic background to cultural contexts, and from role models in the family to everyday parent-child activity, the literature in science education suggests and documents the influence of outside-school factors in students' formation of science attitudes and aspirations, and their attainment in science classes. However, part of this literature is fragmented as each study examines only a small number of relationships (e.g., the influence of family interest in science on students' interest in science). While establishing these relationships is important, we suggest that a broader theoretical framework is needed to help us understand the role of outside-school factors in science education, and the mechanisms through which these factors influence students' attitudes, aspirations and attainment in science. Unlike most frameworks that use only Bourdieu, by incorporating Sen's capability framework we provide a more dynamic view in which initial science-related resources are converted to science-related capabilities, which may or may not then be converted to science-related functionings.

One advantage of our two-stage model is that its relative simplicity makes it quite flexible and practical in addressing potentially important policy questions about the role of outsideschool factors in science education. With our framework, science educators can clearly make the distinction between outcomes (i.e., functionings) and the ability to achieve these outcomes (i.e., capabilities) related to science education. They can also identify the role of specific factors, and how they influence the student, in providing resources or in converting resources to capabilities or functionings. For example, for a student, role models in science in 
the family may act as conversion factors from science-related capability to science-related functioning, but going to museums or doing science-related activities may act as conversion factors from initial science-related resources to science-related capabilities. We hope that our framework will help science educators in recognising these nuances, and lead to better informed policy decisions being made in science education.

Our case study demonstrates and provides evidence for three main ideas suggested in the two-stage model. Specifically, the model's first main idea is that each student is provided with an initial set of science-related resources that are influenced by parental socio-economic status as well as by cultural and ethnic factors and parental attitudes to science. In our cases, Fulya and Derya have greater initial science-related resources than Zeki. The second main idea in the model is the conversion of initial resources to science-related capabilities. While we observe significant conversion leading to a very high level of science-related capability development in Fulya and Derya, the lack of such conversion factors leads Zeki to develop much lower levels of capability development. This low level of science-related capability combined with no major conversion factors in the second stage (from capability to functioning) results in Zeki showing neither positive attitudes towards nor aspirations for science. This second stage conversion from science-related capability to science-related functioning is the third main idea in the model. The difference in the career aspirations of Fulya and Derya reveals the distinction between capabilities and functionings. While Derya is very much interested in a science-career, Fulya is not. Fulya's lack of interest in sciencerelated careers may be a lack of some conversion factors in the second stage (e.g., not seeing the appeal in such a career).

These cases also show how our model can be useful for gaining deeper insights into the role of outside-school factors in science education. For example, without the two-stage model, if one looks at the case of Fulya, one may only see the input and output, that is, an immigrant student from a low socio-economic status background and low aspirations in science. One might then conclude that this is another example of low socio-economic status leading to low aspiration. In fact, Fulya has very well developed science capabilities; outsideschool factors, particularly parental actions, played a significant role in developing and enhancing these capabilities, and her current decision not to pursue a science-related career is her own choice.

Although the focus of this study is outside-school factors, we do not dismiss or lessen the role of in-school factors, nor the interplay between in-school and outside-school factors in shaping students' science capabilities or functionings. While these are important, they are beyond the scope of this paper. In addition, we believe that our model is rich and flexible enough that with some modifications, such as highlighting the role of school as a 'field' (Reay et al., 2009) or examining in-school elements as conversion factors, future work could extend our model by incorporating these elements.

\section{References}

Abbas, T. (2004). The Education of British South Asians: Ethnicity, capital and class structure. Basingstoke, UK: Palgrave-Macmillan.

Abel, T., \& Frohlich, K. L. (2012). Capitals and capabilities: Linking structure and agency to reduce health inequalities. Social Science and Medicine, 74(2), 236-244.

Adamuti-Trache, M., \& Andres, L. (2008). Embarking on and persisting in scientific fields of study: Cultural capital, gender, and curriculum along the science pipeline. International Journal of Science Education, 30(12), 1557-1584.

Archer L., Dawson E., DeWitt J., Seakins A., \& Wong, B. (2015). 'Science capital': a conceptual, methodological, and empirical argument for extending bourdieusian notions of capital beyond the arts. Journal of Research in Science Teaching, 52, 922-948. 
Archer, L., DeWitt, J. \& Wong. W. (2013). Spheres of influence: What shapes young people's aspirations at age 12/13 and what are the implications for education policy? Journal of Education Policy, 29(1), 1-28.

Archer, L., Dewitt, J., \& Willis, B. (2014). Adolescent boys' science aspirations: Masculinity, capital and power. Journal of Research in Science Teaching, 51(1), 1-30.

Archer, L., DeWitt, J., Osborne, J., Dillon, J., Willis, B. \& Wong, B. (2010). 'Doing' science vs 'being' a scientist. Science Education, 94(4), 617-639.

Archer, L., DeWitt, J., Osborne, J., Dillon, J., Willis, B. \& Wong, B. (2012). Science aspirations, capital, and family habitus: How families shape children's engagement and identification with science. American Educational Research Journal, 49(5), 881-908.

Archer. L., DeWitt, J., Osborne, J., Dillon, J., Willis, B. \& Wong, B. (2013). Not girly, not sexy, not glamorous: Primary school girls' and parents' constructions of science aspirations. Pedagogy, Culture and Society, 21(1), 171-194.

Aschbacher, P. R., Li, E., \& Roth, E. J. (2010). Is science me? High school students' identities, participation and aspirations in science, engineering, and medicine. Journal of Research in Science Teaching, 47, 564-582.

Atherton, G., Cymbir, E., Roberts, K., Page, L., \& Remedios, R. (2009). How Young People Formulate their Views about the Future. London: Department for Children, Schools and Families.

Bourdieu, P. \& Passeron, J.-C. (1990). Reproduction in Education, Society and Culture. Vol. 4. London: Sage.

Bourdieu, P. \& Wacquant, L. (1992). An Invitation to Reflexive Sociology. Chicago: University of Chicago Press.

Bourdieu, P. (1977). Outline of a Theory of Practice. Cambridge: Cambridge University Press.

Bourdieu, P. (1990). In Other Words: Essays towards a Reflexive Sociology. Stanford, CA: Stanford University Press.

Bourdieu, P. (1993). Sociology in Question. London: Sage.

Bourdieu, P. (2002). The forms of capital. In Woolsey Biggart, N. (Ed.) Readings in Economic Sociology. Malden, MA: Blackwell, pp. 280-291.

Bransford, J. D. (2006) Toward a 21st Century learning theory: Some emerging thoughts. Paper presented at the Annual Conference of the National Association for Research in Science Teaching, April 3-6, San Francisco, CA.

Braund, M., \& Reiss, M. J. (2006). Towards a more authentic science curriculum: The contribution of out-of-school learning. International Journal of Science Education, 28(12), 1373-1388.

Calabrese Barton, A. (1998). Reframing "science for all" through the politics of poverty. Educational Policy, 12(5), 525-541.

Calhoun, C., LiPuma, E., \& Postone, M. (1993). Bourdieu: Critical Perspectives. Chicago: University of Chicago Press.

Clark, D. A. (2005). The Capability Approach: Its Development, Critiques and Recent Advances. Global Poverty Research Group, Working paper.

Cleaves, A. (2005). The formation of science choices in secondary school. International Journal of Science Education, 27(4), 471-486.

Corbin, J., \& Strauss, A. (2008). Basics of qualitative research. 3rd Edition. London: SAGE.

Crowley, K., Callanan, M. A., Jipson, J. L., Galco, J., Topping, K., \& Shrager, J. (2001). Shared scientific thinking in everyday parent-child activity. Science Education, 85(6), 712-732.

Dabney, K. P., Chakraverty, D., \& Tai, R. H. (2013). The association of family influence and initial interest in science. Science Education, 97(3), 395-409. 
Dawson, E. (2014a). "Not Designed for Us": How science museums and science centers socially exclude low-income, minority ethnic groups. Science Education, 98(6), 981-1008.

Dawson, E. (2014b). Equity in informal science education: Developing an access and equity framework for science museums and science centres. Studies in Science Education, 50(2), 209-247.

Department for Education and Skills (2005). Ethnicity and Education: The Evidence on Minority Ethnic Pupils, Research Topic Paper: RTP01-05. London: DfES.

DeWitt, J., Osborne, J., Archer, L., Dillon, J., Willis, B., \& Wong, B. (2011). Young children's aspiration in science: The unequivocal, the uncertain and the unthinkable. International Journal of Science Education, 35(6), 1037-1063.

Dierking, L. D., \& Falk, J. H. (1994). Family behavior and learning in informal science settings: A review of the research. Science Education, 78(1), 57-72.

Dumais, S. (2002) Cultural capital, gender, and school success: the role of habitus. Sociology of Education, 75, 44-68.

Elias, P., Jones, P., \& McWhinnie, S. (2006). Representation of Ethnic Groups in Chemistry and Physics: A report prepared for the Royal Society of Chemistry and the Institute of Physics. London: Royal Society of Chemistry/Institute of Physics.

Farnell, B. (2000). Getting out of the Habitus: an alternative model of dynamically embodied social action. Journal of the Royal Anthropological Institute, 6, 397-418.

Ferry, T. R., Fouad, N. A., \& Smith, P. L. (2000). The role of family context in a social cognitive model for career-related choice behavior: A math and science perspective. Journal of Vocational Behavior, 57(3), 348-364.

Fusco, D. (2001). Creating relevant science through urban planning and gardening. Journal of Research in Science Teaching, 38(8), 860-877.

Fusco, D., \& Calabrese Barton, A. (2001). Representing student achievements in science. Journal of Research in Science Teaching, 38(3), 337-354.

Gaddis, M. S. (2013). The influence of habitus in the relationship between cultural capital and academic achievement. Social Science Research, 42(1), 1-13.

Gilbert, J., \& Calvert, S. (2003). Challenging accepted wisdom: looking at the gender and science education question through a different lens. International Journal of Science Education, 25(7), 861-878.

Gilmartin, S. K., Li, E., \& Aschbacher, P. (2006). The relationship between secondary students' interest in physical science or engineering, science class experiences, and family contexts: Variations by gender and race/ethnicity. Journal of Women and Minorities in Science and Engineering, 12(2-3), 179-207.

Glaser, B. G. \& Strauss, A. L. (1967). The Discovery of Grounded Theory: Strategies for Qualitative Research. Chicago: Aldine.

Hall, R. L., \& Schaverien, L. (2001). Families' engagement with young children's science and technology learning at home. Science Education, 85(4), 454-481.

Hart, C. S. (2012). Aspirations, Education and Social justice: Applying Sen and Bourdieu. London: A and C Black.

Huang, G., Taddese, N., \& Walter, E. (2000). Research and development report: Entry and persistence of women and minorities in college science and engineering education (NCES 2000-601). Washington, DC: National Center for Education Statistics, U.S. Department of Education.

Kelle, Udo (1995). Introduction: An overview of computer-aided methods in qualitative research. In Udo Kelle (Ed.), Computer-Aided Qualitative Data Analysis: Theory, methods and practice (pp.1-17). London: Sage. 
Keller, E. F. (1995). Reflections on Gender and Science. New Haven, CT: Yale University Press.

Lee, O., \& Fradd, S. (1998). Science for all, including students from non-English-language backgrounds. Educational Researcher, 27(4), 12 - 21.

Lemke, J. (2001). Articulating communities: Sociocultural perspectives on science education. Journal of Research in Science Teaching, 38(3), 296-316.

Maton, K. (2012). Habitus. In Michael Grenfell (Ed.), Pierre Bourdieu: Key Concepts (revised). London, UK: Acumen Publishing.

Miles, M. B., \& Huberman, A. M. (1994). Qualitative data analysis (2nd ed.). London: Sage.

Morison, M. \& Moir, J. (1998). The role of computer software in the analysis of qualitative data: efficient clerk, research assistant or Trojan horse? Journal of Advanced Nursing, 28(1), 106-116.

Mujtaba, T., \& Reiss, M. J. (2014). A survey of psychological, motivational, family and perceptions of physics education factors that explain 15-year-old students' aspirations to study physics in post-compulsory English schools. International Journal of Science and Mathematics Education, 12, 371-393.

Naidoo, R. (2004). Fields and institutional strategy: Bourdieu on the relationship between higher education, inequality and society. British Journal of Sociology of Education, 25(4), 457-471.

Nash, R. (1999) Bourdieu, 'habitus', and educational research: Is it all worth the candle?, British Journal of Sociology of Education, 20, 175-187.

National Research Council (2009). Learning Science in Informal Environments: People, Places, and Pursuits (P. Bell, B. Lewenstein, A. W. Shouse, \& M. A. Feder, Eds). Washington, DC: National Academies Press.

Noguera, P. A. (2003). The trouble with Black boys: The role and influence of environmental and cultural factors on the academic performance of African American males. Urban Education, 38(4), 431-459.

Nussbaum, M. C. (2000). Women and Human Development: The Capabilities Approach. Cambridge: Cambridge University Press.

Olsen, R. V., Prenzel, M. \& Martin, R. (2011). Interest in science: A many-faceted picture painted by data from the OECD PISA study. International Journal of Science Education, $33(1), 1-6$.

Osborne, J. (2007). Engaging young people with science: thoughts about future direction of science education. Proceedings of the Linnaeus Tercentenary Symposium held at Uppsala University, Uppsala, Sweden. May, 28-29.

Rahm, J. (2002). Emergent learning opportunities in an inner-city youth gardening program. Journal of Research in Science Teaching, 39(2), 164-184.

Rahm, J., \& Ash, D. (2008). Learning environments at the margin: Case studies of disenfranchised youth doing science in an aquarium and an after-school program. Learning Environments Research, 11(1), 49-62.

Reay, D. (2004). 'It's all becoming a habitus': Beyond the habitual use of habitus in educational research. British Journal of Sociology of Education, 25(4), 431-444.

Reay, D., David, M., \& Ball, S. (2005). Degrees of Choice: Social Class, Race and Gender in Higher Education. Stoke-on-Trent: Trentham Books.

Reay, D., Hollingworth, S., Williams, K., Crozier, G., Jamieson, F., James, D. \& Beedell, P. (2007) A darker shade of pale: Whiteness, the middle classes and multi-ethnic inner city schooling, Sociology 41(6): 1041-60.

Reay, D., Crozier, G., \& Clayton, J. (2009). 'Strangers in paradise'? Working-class students in elite universities. Sociology, 43(6), 1103-1121. 
Reiss, M. J. (2004). Students' attitudes towards science: A long-term perspective. Canadian Journal of Math, Science and Technology Education, 4(1), 97-109.

Richards, Lyn \& Richards, Tom (1991). The transformation of qualitative method: Computational paradigms and research processes. In N. G. Fielding \& R. M. Lee (Eds), Using Computers in Qualitative Research (pp.38-53). London: Sage.

Riegle-Crumb, C., Moore, C., \& Ramos-Wada, A. (2011). Who wants to have a career in science or math? Exploring adolescents' future aspirations by gender and race/ethnicity. Science Education, 95(3), 458-476.

Roberts, K. A. \& Wilson, R. W. (2002). ICT and the research process: Issues around the compatibility of technology with qualitative data analysis. Forum: Qualitative Social Research, 3(2) Art 23.

Robeyns, I. (2005). The Capability Approach: A theoretical survey. Journal of Human Development, 6(1), 93-114.

Royal Society (2008). Exploring the Relationship between Socio-economic Status and Participation and Attainment in Science Education. London: Royal Society.

Sayer, A. (2005). The Moral Significance of Class. Cambridge: Cambridge University Press.

Schreiber, J. B., \& Chambers, E. A. (2002). After-school pursuits, ethnicity, and achievement for 8th- and 10th-grade students. Journal of Educational Research, 96(2), 90-100.

Schuller, T., Bynner, J., \& Feinstein, L. (2004). Capitals and capabilities. In Downing Street Seminar on Wealth. Centre for Research on the Wider Benefits of Learning, London.

Sen, A. (1985). Well-being, agency and freedom: The Dewey lectures 1984. The Journal of Philosophy, 82(4),169-221.

Sen, A. (1992). Inequality Re-examined. Oxford: Oxford University Press.

Sen, A. (1993). Capability and wellbeing. The Quality of Life, 1(9), 30-54.

Sen, A. (1999). Development as Freedom. Oxford: Oxford University Press.

Silva, E. B. (2005). Gender, home and family in cultural capital theory. British Journal of Sociology, 56(1), 83-103.

Skeggs, B. (2004). Class, Self, Culture. London: Routledge.

Stewart, F. (2005). Groups and capabilities. Journal of Human Development, 6(2), 185-204.

Sugden, R. (1993). Welfare, resources, and capabilities: a review of Inequality Reexamined by Amartya Sen. Journal of Economic Literature, 31, 1947-1962.

Swartz, D. (1996). Bridging the study of culture and religion: Pierre Bourdieu's political economy of symbolic power. Sociology of Religion, 57(1), 71-85.

Tenenbaum, H. R., \& Leaper, C. (2003). Parent-child conversations about science: The socialization of gender inequities? Developmental Psychology, 39(1), 34-47.

Terzi, L. (2005). Beyond the dilemma of difference: The capability approach to disability and special educational needs. Journal of Philosophy of Education, 39, 443-460.

Tesch, R. (1990). Qualitative Research. Analysis Types and Software. London: Falmer Press.

Tooley, J., \& Darby, D. (1998). Educational Research: A Critique. A Survey of Published Educational Research. London: Ofsted.

Tran, N. M. (2011). The Relationship between students' connections to out-of-school experiences and factors associated with science learning. International Journal of Science Education, 33(12), 1625-1651.

Turner, S. L., Steward, J. C., \& Lapan, R. T. (2004). Family factors associated with sixthgrade adolescents' math and science career interests. The Career Development Quarterly, 53(1), 41-52. 
Unterhalter, E. (2003). Crossing disciplinary boundaries: The potential of Sen's capability approach for sociologists of education (review). British Journal of Sociology of Education, 24(5), 665-669.

Vincent, C., Rollock, N., Ball, S., \& Gillborn, D. (2012). Being strategic, being watchful, being determined: Black middle-class parents and schooling. British Journal of Sociology of Education, 33(3), 337-354.

Walker, M. (2005). Amartya Sen's Capability approach and education. Educational Action Research, 13(1), 103-110.

Walker, M., \& Unterhalter, E. (Eds) (2007). Amartya Sen's Capability Approach and Social Justice in Education. New York: Palgrave Macmillan.

Wong, B. (2012). Identifying with science: A case study of two 13-year-old 'high achieving working class' British Asian girls. International Journal of Science Education, 34(1), 4365 . 


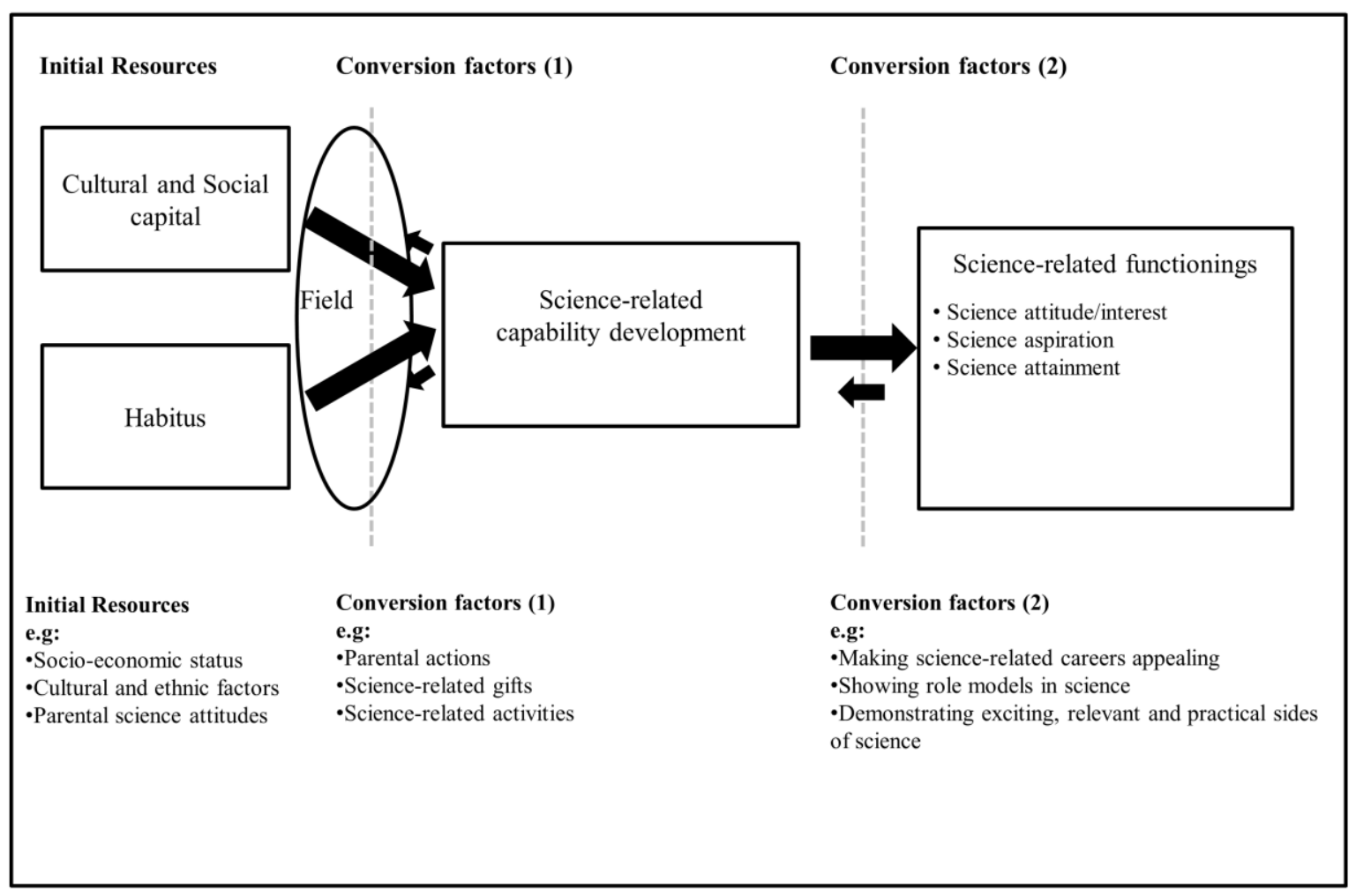

Figure 1 
Table 1. The Cases of Zeki, Fulya, and Derya

\begin{tabular}{|c|c|c|c|c|c|c|}
\hline Student & $\begin{array}{l}\text { Par } \\
\text { ent }\end{array}$ & $\begin{array}{l}\text { Initial } \\
\text { Science- } \\
\text { related } \\
\text { Resource }\end{array}$ & & $\begin{array}{r}\text { Scienc } \\
\text { e-related } \\
\text { Capability }\end{array}$ & & $\begin{array}{c}\text { Science- } \\
\text { related } \\
\text { Functioning }\end{array}$ \\
\hline $\begin{array}{l}\text { Zeki } \\
\text { Year 7, } \\
\text { boy }\end{array}$ & $\begin{array}{c}\mathrm{Ni} \\
\text { hal }\end{array}$ & Low & $\begin{array}{l}\text { Conver } \\
\text { sion } \\
\text { Factors } \\
\rightarrow\end{array}$ & Low & $\begin{array}{c}\text { Conver } \\
\text { sion } \\
\text { Factors } \\
\rightarrow\end{array}$ & $\begin{array}{l}\text { Interest: Low } \\
\text { Aspiration: } \\
\text { Low } \\
\text { Attainment: } \\
\text { High }\end{array}$ \\
\hline $\begin{array}{l}\text { Fulya } \\
\text { Year 7, } \\
\text { girl }\end{array}$ & $\begin{array}{c}\text { Go } \\
\text { nca }\end{array}$ & $\begin{array}{c}\text { Moderat } \\
\mathrm{e}\end{array}$ & $\begin{array}{l}\text { (Stage } \\
1)\end{array}$ & High & $\begin{array}{l}\text { (Stage } \\
2)\end{array}$ & $\begin{array}{l}\text { Interest: } \\
\text { High } \\
\text { Aspiration: } \\
\text { Low } \\
\text { Attainment: } \\
\text { High }\end{array}$ \\
\hline $\begin{array}{l}\text { Derya } \\
\text { Year10, } \\
\text { girl }\end{array}$ & & $\begin{array}{c}\text { Moderat } \\
\mathrm{e}\end{array}$ & & High & & $\begin{array}{l}\text { Interest: } \\
\text { High } \\
\text { Aspiration: } \\
\text { High } \\
\text { Attainment: } \\
\text { High }\end{array}$ \\
\hline
\end{tabular}

Table 1 